\title{
Ballast fouling evaluation with ground penetrating radar
}

\author{
Ana Margarida Marques ${ }^{1, *}$, Simona Fontul ${ }^{2,3}$, and André Paixão $0^{4,5}$ \\ ${ }^{1}$ Nova University of Lisbon, Faculty of Science and Technology, Caparica, Portugal \\ ${ }^{2}$ National Laboratory for Civil Engineering, Department of Transportation, Lisbon, Portugal \\ ${ }^{3}$ Nova University of Lisbon, Faculty of Science and Technology, Department of Civil Engineering, \\ Caparica, Portugal \\ ${ }^{4}$ LNEC, Department of Transportation, Lisbon, Portugal \\ ${ }^{5}$ CONSTRUCT - LESE, Faculty of Engineering (FEUP), University of Porto, Portugal
}

\begin{abstract}
In the transport infrastructures context, the support layers have a fundamental role in the degradation of the track condition, both in structural aspects and in terms of fouling of the materials that comprise them. Particularly in the field of railway research, ballast is the key element, and its fouling leads to track deterioration. Thus, the main focus of this work is based on the evaluation of the ballast fouling using Ground Penetrating Radar (GPR). In order to determine the applicability of the method on the evaluation of railway characteristics, laboratory samples and measurements carried out in situ, on sections of two railways in operation were analysed. In both cases the different ballast fouling levels were evaluated, using specialized software for this approach (temporal analysis); and then comparing these results with results of a frequency analysis in an automatic calculation program. This paper presents the possibilities of testing with GPR equipment by analysing an electromagnetic wave, in the temporal and frequency domain for the purpose of investigating the level of degradation of a railway track. Some recommendations are also made regarding the use of this method, adding the need for future developments in an attempt to reduce the number of destructive tests still practiced nowadays.
\end{abstract}

\section{Introduction}

The degradation of the railway track is a complex process that involves the influence of several factors that may condition its performance during the life cycle of the structure and consequently the durability of the track itself. Considering that a railway deteriorates rapidly over time, knowing the degradation process will help in estimating the future state

\footnotetext{
*Corresponding author: am.marques@campus.fct.unl.pt
} 
of track conditions and mitigating problems associated with operational safety. Thus, in order to make the management of railway infrastructure more efficient, it is essential to locate, in an early and more expeditious way, areas that need intervention / rehabilitation actions. In this context, GPR has been identified as a tool with significant potential, having acquired great relevance in recent years. GPR is generally used for continuous assessment of railway infrastructure, mainly to assess the thickness of the ballast layer and changes in the structure [1-5]. However, the results obtained by classical signal analysis (in the time domain) have not been satisfactory or consistent when used in assessing the condition of the ballast, in particular as regards its contamination. Recent studies highlighted the potential of the application of this tool in the detection of the condition of the material when analysed the signal variability in the frequency domain, the main focus of this work. Thus, two case studies were analysed in order to deepen the knowledge regarding the GPR technique. The proposed methodology consists in establishing relationships between the results obtained by the classical time domain approach and the results obtained in the frequency domain; in order to obtain information to support maintenance intervention decisions at the level of the rail network.

\section{Main factors of the ballast fouling material}

The behaviour of ballast depends, among other factors, on its intrinsic characteristics, such as [6]: the nature, shape and physical properties of the aggregates (porosity, hardness, wear resistance, alterability, etc.); the grading curve adopted (in particular, the percentage of fines); and the quantity of the gravel elements. With regard to the ballast fouling material, it is verified that there are some factors that contribute to its contamination, taking to poor service conditions. In general, the origin of these phenomena may be:

a) Traffic factors, due to the imposed stresses, the sleepers tend to rise and settle back into the ballast layer, the impact caused by the dynamic stresses can overload the ballast and lead to breakage, sliding and abrasion of its particles;

b) Factors associated with soil characteristics, namely the change in the mechanical characteristics of the various elements;

c) Environmental factors (water content and soil temperature).

It should be noted that for a correct evaluation of the railway track, it is necessary to take into account the influence of all these factors, not only its evolution / degradation in isolation, but mainly as a whole.

\section{Principles of GPR}

\subsection{Electromagnetic properties of materials}

According to the literature of the specialty, the principle of the GPR method is based on the electromagnetic wave theory or theory of electromagnetism, established by Maxwell in 1880. Geological materials have the ability to propagate electromagnetic energy and this propagation essentially depends on three parameters: a) magnetic permeability, b) dielectric constant and c) electrical conductivity of materials. The most important electromagnetic property is the relative dielectric constant, also known as dielectric value or relative dielectric permissivity. This parameter is defined by the following expression:

$$
\varepsilon_{r}=\frac{\varepsilon_{m}}{\varepsilon_{0}}
$$


where $\varepsilon_{m}$ is the absolute permissivity of the material and $\varepsilon_{0}$ permissivity of the vacuum $\left(8,85 \times 10^{-12} \mathrm{~F} / \mathrm{m}\right)$. The relative dielectric constant of a material controls the propagation velocity of the electromagnetic waves, as well as reflection and refraction of the signal in the low conductivity and non-magnetic permeability media. Okrasinski studied the effect of some materials characteristics, such as porosity and water content, on the dielectric constant [7], and concluded that this parameter decreases with increasing porosity (regardless of soil type) and increases with the water content.

\subsection{Wave propagation in a ballast layer}

Whenever electromagnetic waves reach an interface between two layers with distinct electrical properties, they will undergo several phenomena that affect their behaviour (reflection, dispersion, refraction and diffraction). In this analysis, wave reflection is the most important phenomenon and for this reason will be the main focus, because GPR captures and records only the reflected part of the wave. Thus, the greater the difference between the electrical properties of the different layers, the greater the reflection for the surface and the greater the amplitude of the signal read by the equipment.

The reflected energy will reach the receptor at different times depending on the dielectric values of the materials detected during wave propagation, forming a more or less clear image according to the reflection coefficient. This reflection is generally distinguished by a significant amplitude variation of the signal, having a releasable waveform relative to the remaining part. The amplitudes are then recorded as a time function and a trace is generated.

According to Figure 1, it is clearly observed: (a) the location of the object in the first situation, through the reflection that is generated, it is possible to determine the depth of its location. (b) A single impulse is visible although with greater amplitude, this translates reflections from the top and bottom of the thin layer, shown on the left; since these are so close, the equipment can only detect its presence, making it impossible to determine the corresponding thickness. (c) On the other hand, in the presence of a thick layer, through the radar it is possible to identify a clear interface between the two layers, represented by two distinct pulses characterizing the upper and lower limits of the second layer. In this way, it is possible to determine the depth to which this new layer starts as well as its thickness, this case corresponds to the ideal situation when using this type of method. (d) The last situation, where there is a gradual increase in the dielectric value, suggests the existence of a layer with

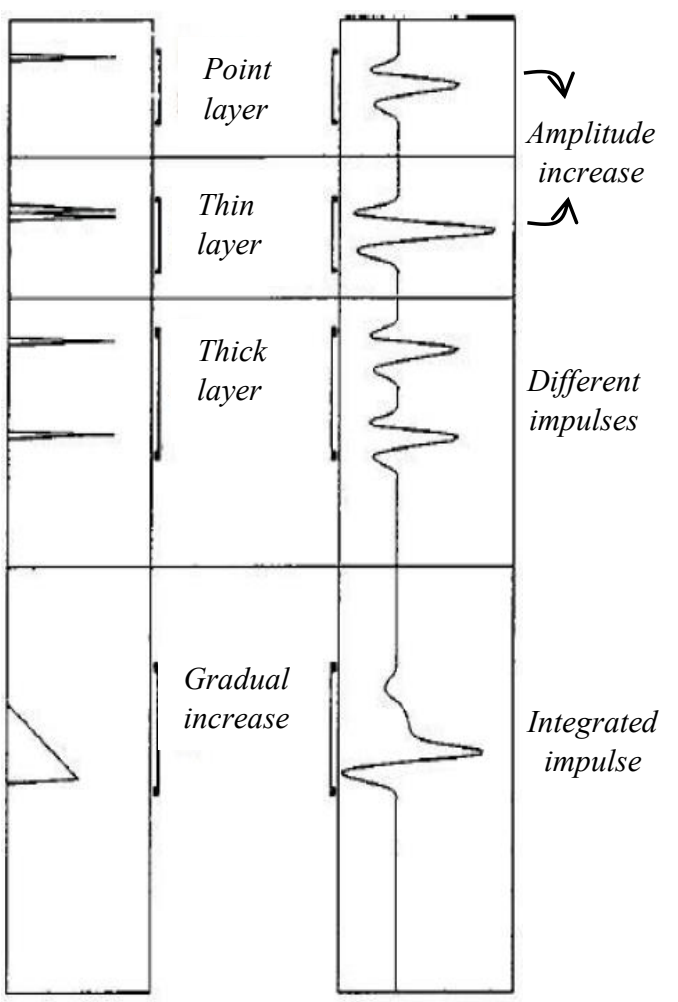

Figure 1 - Examples of reflections [8] increasing levels of water content [8]. 
This happens in situations where the contamination of the rail ballast with fine soils (in depth) occurs, for example. There is no boundary that delimits the clean ballast layer from which it is heavily contaminated, but rather a progressive increase in the degree of contamination; a factor that must be taken into account when interpreting the results of a railway.

\subsection{Applications of the method}

From the beginning, the GPR has been used for various purposes in all kinds of investigations. In order to show the potential of this equipment, the following different fields of application are indicated: geology, archeology, forensic science, astronomy, cartography, mining exploration, environmental studies, topography, among others. In Portugal, GPR has been applied very recently in solving structural problems and in prospecting buried infrastructures.

\section{Case Study}

Different computational tools were used that allowed to evaluate several characteristics of the railway track. Data were collected both in the laboratory and in situ, using antennas with different frequencies. The detailed conditions of these laboratory measurements are described in the documents [1, 9-10], where all the laboratory work involved is described, as well as the results obtained in these same evaluations. The data collected in situ comes from two distinct railway lines - one in Portugal (sections A, B, C, D and E) and another on the African Continent (sections F and G).

From the information that can be provided it is known that the first railway line has some heterogeneity, and the implantation of its elements occurred basically in four different periods. It is also observed that, associated to the bad condition of the track geometry, there are other deficiencies that correspond naturally to its cause, such as the state of the rail and the drainage. Thus, Table 1 summarizes the main characteristics associated with the study line.

Table 1 - Characteristics of the infrastructure analysed with the $400 \mathrm{MHz}$ antenna

\begin{tabular}{|c|c|c|c|c|}
\hline Sections & $\begin{array}{c}\text { Extended } \\
\text { Intervention }(\mathrm{m})\end{array}$ & Type of ballast & Type of sleepers & $\begin{array}{l}\text { Condition of the } \\
\text { track geometry }\end{array}$ \\
\hline A & 260 & Granitic & Biblock & Deficient \\
\hline B & 110 & Granitic & Biblock & Deficient \\
\hline $\mathrm{C}$ & 140 & Granitic & Biblock & Deficient \\
\hline $\mathrm{D}$ & 370 & Granitic & Biblock & Deficient \\
\hline E & - & - & $\begin{array}{l}\text { Biblock and } \\
\text { Timber }\end{array}$ & Poor \\
\hline
\end{tabular}

The second railway line has been recently reactivated to enable the transport of minerals by railway vehicles. It was also verified that it is a railway without sub-ballast layer, that is, in which the ballast layer rests directly on the foundation soils, which does not always exhibit the best geotechnical characteristics. After performing the radar tests along the line, wells were also made in the ballast layer in order to measure the thickness, thus helping to calibrate the signal propagation velocities in the radargrams obtained with the equipment. These results are presented in Table 2. It should be noted that two types of radar system were used, namely: IDS-Radar (Ingegneria Dei Sistemi) with a frequency of $400 \mathrm{MHz}$ and GSSI (Geophysical Survey Systems Inc.) with a frequency of $1000 \mathrm{MHz}$; taking the care 
and attention of the specificities of each one. The first antenna was used in sections A, B, C, $\mathrm{D}$ and $\mathrm{E}$ and the last one in sections $\mathrm{F}$ and $\mathrm{G}$.

Table 2 - Characteristics of the infrastructure analyzed with the $1 \mathrm{GHz}$ antenna

\begin{tabular}{|c|c|c|c|c|c|c|}
\hline \multirow{2}{*}{ Sections } & \multirow{2}{*}{ Type of sleepers } & \multirow{2}{*}{$\begin{array}{l}\text { Thickness of } \\
\text { sleepers }(\mathrm{cm})\end{array}$} & \multicolumn{3}{|c|}{ Thickness of ballast $(\mathrm{cm})$} & \multirow{2}{*}{ Dielectric value } \\
\hline & & & Clean & Fouled & Total & \\
\hline $\mathrm{F}$ & Monoblock & 20 & 14 & 0 & 14 & 6,5 \\
\hline G & Monoblock & 20 & 15 & 33 & 48 & 12 \\
\hline
\end{tabular}

\subsection{Temporal analysis}

Using a time domain analysis, two parameters were evaluated: the GBFI contamination index and the water content. Thus, using a commercial interpretation program, the laboratory results obtained for the GBFI index (by both antennas) were very different, and there was no coherence in the values obtained, which made it impossible to establish a range of values associated with each index. However, for in situ measurements the program showed sensitivity in locating areas that are more deteriorated, so it can be said that qualitatively the results obtained may be interesting, although at a quantitative level they are far from what was expected. Regarding the water content, the laboratory measurements showed minor changes when the water content level in the medium was evaluated for both IDS and GSSI antennas. On the other hand, in the data measured in situ, the variation of this parameter was notorious when detecting the most contaminated zones.

\subsection{Frequency analysis}

In recent research to determine the quality of track ballast, a less conventional approach has been taken: frequency analysis of the signal. According to the information collected, the distinction between "clean ballast" and "fouled ballast" can be made with the frequency information coming from the GPR signal [11]. It is known that the high content of fines and the increase of the amount of absorbed water causes a dielectric dispersion, which allows this analysis. All signals in the time domain are represented by a single value describing their amplitude at any instant in time. In this sense, by using a transform, known as Fast Fourier Transform (FFT), it is possible to obtain this same signal in the frequency domain. The purpose of this method is to convert the data collected by the time domain to the frequency domain, thus allowing to analyse the different frequency contributions that make up the registered GPR signal and consequently to obtain information on the quality of the material. In Figure 2, an example of a GPR signal obtained in the time domain (a) and the same signal represented in the frequency spectrum (b) is presented.
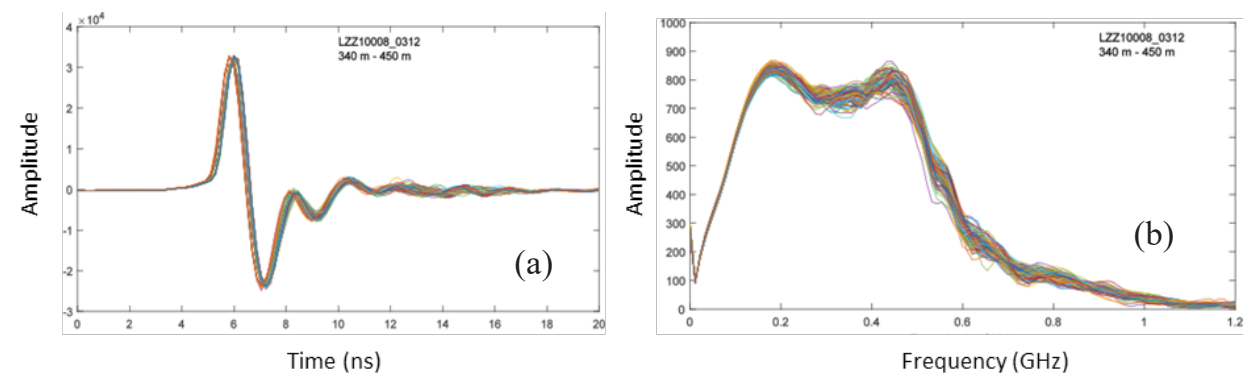

Figure 2. Results obtained for section B, in the time domain (a) and frequency domain (b). 
In a second phase, specific points of the frequency spectrum were analyzed for a more detailed evaluation. As shown in Figure 3, the approaches considered concern: i) reading amplitudes at specific points (A and B); ii) analysis of the variation of two pre-defined amplitudes (C) and iii) analysis of the slope of a section of the graph (D).

From the results obtained, it was verified that the most notorious parameters correspond to the first approaches, that is, the analysis of amplitudes A and B and the analysis of the variation of amplitudes (C). In relation to the slope (D), a great diversity of results was obtained, which were not enlightening in this study.

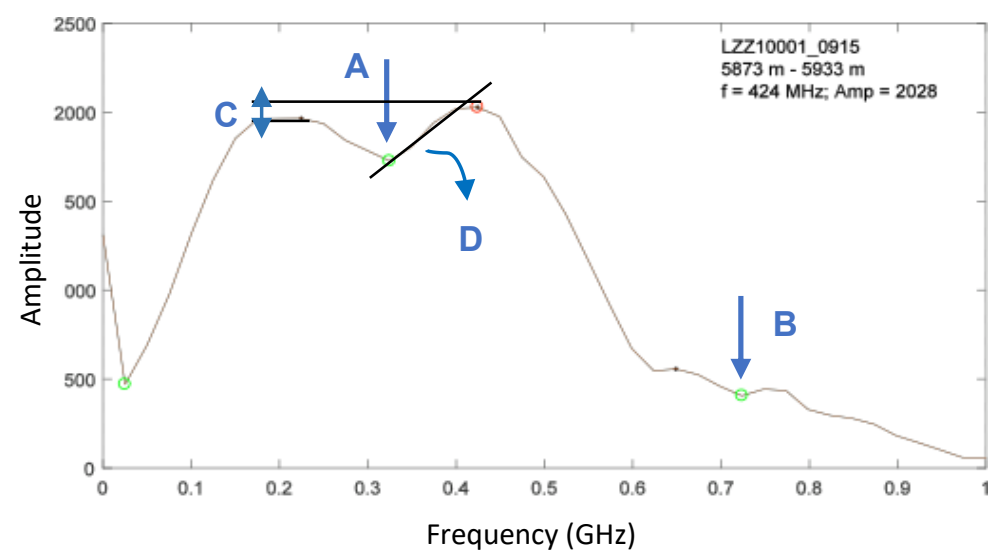

Figure 3. Parameters evaluated in a second phase.

\section{Conclusions}

Railway research efforts are carried out not only to solve the problems of degradation, but also to determine the contribution of each parameter in the whole process. This paper aims to contribute to the improvement of the use of non-destructive techniques in the characterization of support layers, specifically in the detection of the level of contamination of the rail ballast in the presence of fine particles.

The approach presented herein represent an important tool in the sense of selecting efficiently, well-defined, zones that need intervention or rehabilitation. The aim is to contribute to the identification of critical areas and, if possible, to predict future defects, in a non-destructive, continuous way.

\section{References}

[1] F. De Chiara, Improvement of railway track diagnosis using Ground Penetrating Radar, Doctoral dissertation, University of Rome "Sapienza", Rome (2014)

[2] T. Saarenketo, T. Scullion, Journal of Applied Geophysics, 43, 119-138 (2000)

[3] B. Indraratna, L. Su, C. Rujikiatkamjorn, Can. Geotech. J., 48, 322-326 (2011)

[4] N. Tennakoon, B. Indraratna, C. Rujikiatkamjorn, S. Nimbalkar, 11th Australia - New Zealand Conference on Geomechanics: Ground Engineering in a Changing World, 421-426, Australia (2012)

[5] E. Selig, J. Waters, Track Geotechnology and Substructure Management, London: Thomas Telford Publications (1994) 
[6] A.B. Machado, Contribuição para a avaliação estrutural de infraestruturas rodoviárias por Métodos Não Destrutivos, Masters degree thesis, FCT, Nova University of Lisbon, Lisbon (2012)

[7] T.R. Sussmann, Application of ground penetrating radar to railway track substructure maintenance management, Doctoral Dissertation, University of Massachusetts, Amherst, USA (1999)

[8] M.J.N. Pedrosa, Caracterização da fundação de infra-estruturas de transporte com recurso ao georadar. Identificação das camadas de apoio, Masters degree thesis, FEUP, University do Porto, Porto (2009)

[9] A.M. Lopes, Avaliação da degradação de vias férreas. Caracterização do balastro com recurso ao georadar, Masters degree thesis, FCT, Nova University of Lisbon, Lisbon, (2013)

[10] F. De Chiara, s. Fontul, F. Fortunato, Remote Sensing 6 (2014)

[11] M. Silvast, S. Nurmikolu, B. Wiljanen, M. Levomaki, Proc. IMechE 224 Part F, Journal Rail and Rapid Transit (2010) 